\title{
Responses to losses in high-deductible health insurance: persistence, emotions, and rationality
}

\author{
MARK V. PAULY* \\ Department of Health Care Management, The Wharton School, University of Pennsylvania, Philadelphia, \\ PA, USA \\ HOWARD KUNREUTHER \\ Risk Management and Decision Processes Center, The Wharton School, University of Pennsylvania, \\ Philadelphia, PA, USA
}

\begin{abstract}
There have been few empirical studies on how consumers respond to their loss experience over time when choosing between high- and lowdeductible health insurance plans. To address this question, we designed a ten-period web-based experiment to explore how subjects respond to the presence or absence of illness-related costs in a given period when making their future health insurance choices when they are explicitly informed that future premiums or loss probabilities will not change over time. A sizable minority of the respondents who initially chose high-deductible plans switched after a loss, and switching is more likely if they self-report negative emotional responses to experiencing an uninsured loss. Switching from lowto high-deductible plans is less likely and less responsive to loss experience. The study reveals that many individuals make their health insurance choices by considering factors not included in classical economic models of choice.
\end{abstract}

Submitted 11 October 2018; revised 28 October 2018; accepted 9 November 2018

\section{Introduction}

As with insuring against hurricanes and other natural disasters, emotions can impact decisions on appropriate health insurance choices. Prior empirical studies on changes in the demand for health insurance find that when

\footnotetext{
* Correspondence to: Department of Health Care Management, The Wharton School, University of Pennsylvania, 208 Colonial Penn Center, 3641 Locust Walk, Philadelphia, PA 19104, USA. Email: pauly@wharton.upenn.edu
} 
individuals can decide between options, they are more likely to switch to different coverage levels for one of three reasons (Phelps, 1973; McGuire, 2012):

- If premiums change while benefits remain constant;

- If benefits change while premiums remain constant;

- If premiums and benefits do not change but the buyer's risk or attitude to risk changes.

The behavior of consumers in purchasing insurance is not always consistent with expected utility maximization. With respect to health insurance, empirical studies reveal that individuals often make errors in their choices, such as maintaining the status quo and imperfect information, which they only partially correct later (Neipp \& Zeckhauser, 1985; Samuelson \& Zeckhauser, 1988; Abaluck \& Gruber, 2011; Ketcham et al., 2012, 2015). For example, some of these studies reveal that individuals choose less than ideal drug insurance, given their expected expenditure on particular drugs, and may only gradually move toward better-tailored coverage. Furthermore, they appear to be slow in revising their coverage when external factors like premiums relative to expected benefits or their risk levels change.

A gap exists in this literature, however, regarding whether some people erroneously revise their health insurance purchasing decisions over time based on their loss experience when there is no change in premiums, benefits, and the buyer's attitude toward risk. This question is especially important as health insurance buyers have greater ability today to choose between coverage with high and low deductibles, given the prevalence of both these options in group insurance and individual insurance exchanges (Kaiser Family Foundation, 2017). In the federal insurance exchanges, people can switch annually between four types of plans, two with high deductibles (bronze and silver) and two with lower deductibles (gold and platinum). In 2017, the average deductibles were $\$ 6092$ and $\$ 3574$ for bronze and silver, versus \$1197 and \$405 for gold and platinum (HealthPocket, 2017). Options are somewhat more limited in employment-based group insurance (to two or three plans), but most workers with such coverage are in large firms that do offer choices and often offer a high-deductible plan as one of these choices.

A recent empirical analysis of group health insurance with varying deductibles by Bhargava et al. (2017) found that more than half of the respondents chose a dominated plan with a lower deductible, even when the higher-deductible alternative had a premium reduction greater than the increase in the deductible. The study did not, however, explore whether subjects switched either away from a dominated plan or to a dominated plan after a loss or whether their choice of plans was tied to emotions. 
In the USA, one has the possibility of switching among plans with different premiums and coverages, but this is not true in other countries, except Singapore. ${ }^{1}$ For example, in the UK, one cannot choose a high-deductible plan under the UK National Health Insurance program. In countries such as Switzerland, where there are multiple plans, all plans are legally required to offer similar coverage.

This paper provides new experimental evidence from a controlled, multiperiod setting with high- and low-deductible health insurance options, where the external circumstances that should influence choice are explicitly specified to be identical over time. We are interested in knowing the percentage of people that revise their insurance policies in response to their loss experience and why they do so. To this end, we devised an experiment in which people could switch to different coverage levels, enabling us to infer a rationale for their behavior. The experiment asks individuals to choose between a single high-deductible plan and a single low-deductible plan with no other costsharing or managed care dimensions. Subjects' attention is thus focused on relative premiums and coverage given well-specified probabilities of suffering an illness. Our intent is to see whether these clearly framed options coupled with previous losses (illnesses) provoke behavior that depends to some extent on emotions such that the choice of the health insurance plan differs from what would be predicted if the person had maximized his or her expected utility.

This setting reflects - in a highly simplified manner - the options in health insurance markets in the USA after the passage of the Affordable Care Act ("Obamacare") when there was a mandate for people to have at least some coverage. High-deductible plans are an option today in private health insurance markets in the USA and are now chosen by nearly $30 \%$ of consumers in group insurance plans. The most popular plans provided by the Affordable Care Act exchanges are the two high-deductible (bronze and silver) plans. In open enrollment in 2017, for individuals purchasing health insurance via marketplace exchanges, $23 \%$ of buyers chose bronze plans and $71 \%$ chose silver plans (Centers for Medicare and Medicaid Services, 2017). Only $6 \%$ of buyers chose the low-deductible gold or platinum plans (Center for Medicare and Medicaid Services, 2017).

There is little analysis of consumer characteristics related to switching into or out of high- or low-deductible plans when individual choice is possible, as it often is. Our primary interest in this paper is not why these plans were

1 Singapore has permitted the offering of multiple levels of coverage with different deductible options. 
chosen initially, but rather, how often individuals switch away from their first choice as their insurance-related experience accumulates, and whether the emotions generated by expenditures on illnesses play a significant role in their decision to change their deductible.

\section{The experimental setting}

Participants could choose at the beginning of each of ten periods between a high-deductible and a low-deductible insurance plan in the face of a fixed and unchanging risk distribution. In other words, the probabilities and potential costs of contracting and treating moderate or severe illnesses are explicitly stated at the same values in each period regardless of the insurance plan chosen and the person's previous loss experience. Hence, there is never any change in the expected insurance benefits or costs over time, whether or not the person suffered any type of illness in previous periods.

We chose this structure to isolate consumer behavior in a situation where there would be no economic reason for individuals to change their health insurance coverage from their choice in the previous period if they were maximizing their expected utility. The experiment was designed to determine whether emotions experienced after learning the outcome in period $t$ impact the choice of the insurance plan purchased in period $t+1$.

We tested the hypothesis that individuals experienced feelings of regret when they chose a high-deductible plan and experienced an illness that required them to incur a higher out-of-pocket payment than if they had selected a low-deductible plan. These feelings of regret may lead the person to switch to a lowdeductible plan in the next period. Conversely, a person who paid the higher premium associated with a low-deductible plan and did not suffer an illness may decide that the extra premium was wasted and switch to a high-deductible plan in the next period. Although there has been theoretical research that regret may influence insurance purchase decisions (Bell, 1982; Loomes \& Sugden, 1982; Braun \& Muermann, 2004), there have been no empirical studies of the role that regret and the emotions it generates plays in the decision to switch insurance policies over time.

The data for making choices in the experiment were hypothetical rather than reflecting the large premiums and medical expenses corresponding to actual high- and low-deductible plans. The benefits of an experimental setting where one can control the variables of interest by excluding other insurance plan characteristics have to be traded-off against the reduced incentives and motivation associated with hypothetical choices. To the extent that hypothetical choices are likely to be more random and less well-thought-out than actual choices, the experimental results will be biased toward finding no relationship 
between emotions and choice, even if there were a significant relationship in actual behavior. Conversely, statistically significant findings in an experimental setting that support specific models of choice provide strong confirmation for the hypotheses being tested given that there is a bias toward rejecting these predictions due to random behavior. In fact, we do find confirming evidence for the role that emotions play in health insurance decisions, implying that the experiment might underestimate the influences of the variables associated with the models we examine.

\section{Health insurance experimental design}

The experiment consisted of a ten-period game in which participants were asked to imagine that they are 35 years old with a middle-class income. They were told at the outset of the experiment that the game would consist of ten periods and that in each period they would either suffer no illnesses, a moderate illness, or a severe illness with respective probabilities of $0.60,0.35$, and 0.05 . That is, they were explicitly told that an illness of any severity in one period had no effect on the illness probabilities in later periods. If the participant suffers no illnesses, he/she incurred no cost for treatment. The participants were told that the cost of treating a moderate illness was $\$ 500$ and the cost of treating a severe illness was $\$ 20,000$. The instructions for making a choice between a highand low-deductible plan in each period repeated the description of possible outcomes and their probabilities so as to make the time-consistency of those parameters highly salient to the subjects in the experiment.

Participants were required to purchase one of two health insurance policies at the start of each period - Policy A is a high-deductible plan (\$2000) and Policy B is a low-deductible plan (\$100). The expected values of benefits for each period under the high- and low-deductible plans were $\$ 900$ and $\$ 1135$, respectively. Participants were not told the expected benefits of the two plans, but could determine them with the information they had in hand. The high-deductible policy in each scenario always had a lower premium than the low-deductible policy, but the relative premiums for pairs of policies were varied across subjects. Table 1 summarizes the low, medium, and high premiums relative to claims and the associated premium differentials. Approximately a third of participants were offered subsidized policies relative to an actuarially fair price, so the premiums for both the high- and low-deductible policies were less than the expected benefits. A low premium had a negative differential loading, as shown in Table $1 .^{2}$ The other participants were offered

2 The differential loading between policies A and B is defined by the following ratio: (Premium Differential - Claims Differential) / Premium Differential. 
Table 1. Low, medium, and high premiums for Policy A and Policy B and beneficiary choice

\begin{tabular}{llllc}
\hline \hline & \multicolumn{1}{c}{ Policy A } & \multicolumn{1}{c}{ Policy B } & Difference & Differential loading \\
\hline & $\begin{array}{l}\text { High deductible } \\
(\$ 2,000)\end{array}$ & $\begin{array}{l}\text { Low deductible } \\
(\$ 100)\end{array}$ & & \\
Expected benefits & $\$ 900$ & $\$ 1135$ & 235 & - \\
Low premium & $\$ 720$ & $\$ 910$ & 190 & -0.24 \\
Medium premium & $\$ 1080$ & $\$ 1360$ & 280 & 0.16 \\
High premium & $\$ 1260$ & $\$ 1590$ & 330 & 0.29 \\
\hline \hline
\end{tabular}

an option where the premiums were higher than the actuarially fair price due to a loading factor that reflects the administrative costs that insurance companies add to the prices of premiums. A third of the participants were offered insurance premiums slightly above the actuarially fair price (differential loading of 0.16) and a third were offered somewhat higher premiums relative to expected benefits (differential loading of 0.29). The expected values of the probabilities of an illness and the related expenses did not change as a function of the type of insurance policy chosen.

After selecting a health insurance policy, the participant was notified of his/ her illness in that period. If the participant had purchased the high-deductible plan in a given period and suffered a moderate illness, he/she was responsible for the premium and the full cost of treatment $(\$ 500)$, since the loss was less than the deductible. If the participant had purchased the low-deductible plan in a given period and suffered a moderate illness, he/she was responsible for the premium and the first $\$ 100$ of the cost of treatment. If the participant had purchased the high-deductible plan in a given period and suffered a severe illness, he/she was responsible for the premium and the first $\$ 2000$ of the cost of treatment, in contrast to those who had purchased a low-deductible plan, where they would have to pay only the first $\$ 100$ of the treatment cost in addition to the premium. If the participant suffered no illness in a given period, he/she was responsible only for the premium of the plan chosen. Note that, in all cases, the person has higher premiums for the low-deductible policy, but lower out-of-pocket expenses with a moderate illness than if the high-deductible policy were chosen. Should there be no illnesses, the high-deductible/lowpremium plan is always the better deal.

After making their health insurance purchases for the given period, participants were told whether they experienced no illnesses, a moderate illness, or a severe illness. Participants then answered the following question: "How do you feel about having bought Policy A/Policy B now that you know that you had no 
illnesses/a moderate illness/a severe illness?" The following five-point response scale was used to define the variable FEEL:

\begin{tabular}{cccccc} 
A great deal of regret & Some regret & Unaffected & Glad & Very Glad \\
\hline 1 & 2 & 3 & 4 & 5 \\
\hline \hline
\end{tabular}

Each participant in the sample completed ten periods of the game with the same conditions. The experiment was designed such that a third of the participants suffered a severe illness in Period 2, a third suffered a severe illness in Period 8, and a third never suffered a severe illness. Any participant who suffered a severe illness in Period 2 was precluded from suffering a severe illness in Period 8, so that two-thirds of the sample suffered one severe illness. Other participants had a one in three chance of suffering a moderate illness in either Period 2 or Period 8 , so that the chance of a moderate illness was $1 / 3 \times 2 / 3$ or about $22 \%$ in one of these two periods. In the other eight periods, there was a one in three chance that any participant could suffer a moderate illness, whether or not they had suffered a severe illness. Participants could not communicate with each other and so had virtually no way of determining from experience what the frequency of illness was in the experimental setting.

The experiment was conducted on a web-based platform (Qualtrics) with 1567 adults in the final sample. There was no explicit monetary reward for a successful choice, but participants in the experiment were volunteers presumably eager to play the game well. Before a participant began the ten-period game, he/she was asked two hypothetical questions to make sure that he/she understood the nature of the experiment and the impact of specific health insurance decisions on his/her out-of-pocket payments in any given period. Individuals who did not correctly answer at least one hypothetical question were excluded from participating in the experiment. Individuals who correctly answered only one hypothetical question were instructed to reread the instructions, but were allowed to participate in the experiment.

\section{Choice consistency}

Approximately half of all subjects switched from one deductible plan to the other at some point in the experiment, even though there were no changes over time in the risks of experiencing an illness or the costs of health insurance. 
Regardless of their degree of risk aversion, subjects offered the subsidized lowest premiums should always choose the low-deductible plan. (The incremental premium they would pay for the low-deductible policy [\$190, row 2 of Table 1] is less than the incremental expected benefits [\$235, row 1 of Table 1], so any risk-averse or risk-neutral expected utility maximizer should prefer the low-deductible policy.) Moderately risk-averse individuals facing the higher premiums with positive loadings would be more likely to choose the high-deductible plan.

Figure 1 shows the actual pattern of choices of the high-deductible plan over time. Except for Period 1, the proportion of subjects choosing the high-deductible plan (Policy A) is consistently higher if they were in the high-premium group than in the other two premium groups. However, about a third of the subjects who were offered the subsidized premium still chose the high-deductible plan, as shown by the dashed line in Figure 1, inconsistent with expected utility maximization. There is a statistically significant difference between the greater percentage of individuals purchasing the high-deductible plan (Policy A) when faced with the high premium compared with the other two premiums; however, there is no statistical difference between the percentage purchasing Policy A for those offered medium and low premiums.

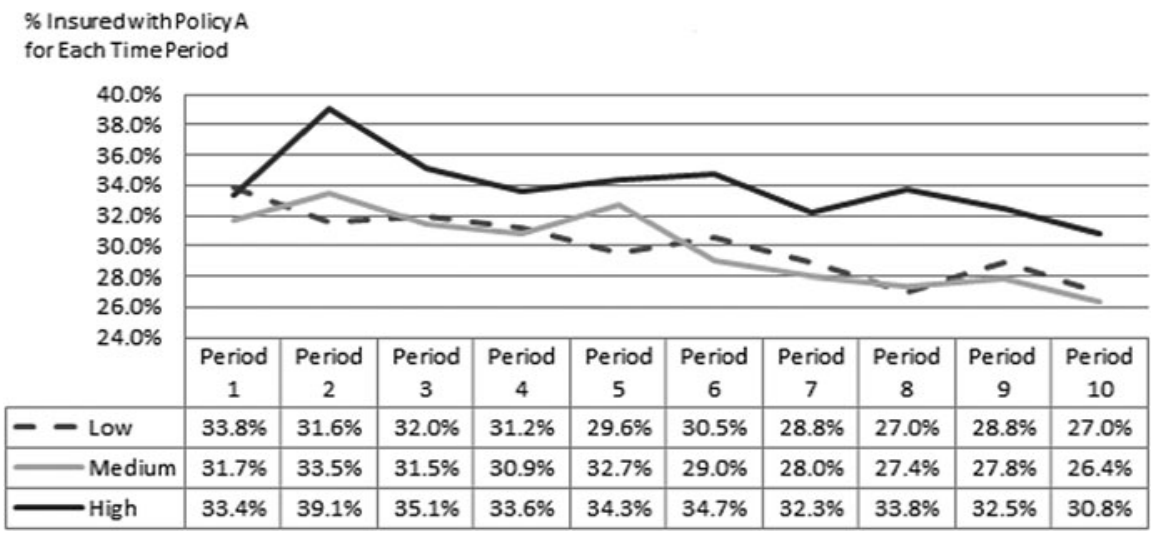

Figure 1. Percentages of individuals purchasing high-deductible plans at low, medium, or high premiums

\section{Reactions to loss experience}

To evaluate respondents' ex post feelings about the insurance choices they made, we define a binary variable equal to 1 to represent those individuals with FEEL scores of 3-5 (HIGH FEEL) and 0 with FEEL scores of 1-2 (LOW FEEL). Looking across rows in Table 2, a larger proportion of 
Table 2. Proportion of high-deductible and low-deductible buyers who have HIGH FEEL scores after no illness and any illness by period

\begin{tabular}{|c|c|c|c|}
\hline $\begin{array}{l}\text { Policy A (high deductible) in Period } 1 \\
\text { Policy B (low deductible) in Period } 1\end{array}$ & $\begin{array}{l}\text { No illness } \\
0.88 \\
0.70 \\
n=1058\end{array}$ & $\begin{array}{l}\text { Any illness } \\
0.45 \\
0.95 \\
n=509\end{array}$ & $\begin{array}{l}\text { Chi-square test } \\
p<0.001 \\
p<0.001\end{array}$ \\
\hline $\begin{array}{l}\text { Policy A (high deductible) in Period } 2 \\
\text { Policy B (low deductible) in Period } 2\end{array}$ & $\begin{array}{l}\text { No illness } \\
0.92 \\
0.69 \\
n=711\end{array}$ & $\begin{array}{l}\text { Any illness } \\
0.46 \\
0.97 \\
n=856\end{array}$ & $\begin{array}{l}\text { Chi-square test } \\
p<0.001 \\
p<0.001\end{array}$ \\
\hline $\begin{array}{l}\text { Policy A (high deductible) in Period } 3 \\
\text { Policy B (low deductible) in Period } 3\end{array}$ & $\begin{array}{l}\text { No illness } \\
0.94 \\
0.74 \\
n=1056\end{array}$ & $\begin{array}{l}\text { Any illness } \\
0.43 \\
0.98 \\
n=511\end{array}$ & $\begin{array}{l}\text { Chi-square test } \\
p<0.001 \\
p<0.001\end{array}$ \\
\hline $\begin{array}{l}\text { Policy A (high deductible) in Period } 4 \\
\text { Policy B (low deductible) in Period } 4\end{array}$ & $\begin{array}{l}\text { No illness } \\
0.93 \\
0.72 \\
n=1028\end{array}$ & $\begin{array}{l}\text { Any illness } \\
0.49 \\
0.97 \\
n=539\end{array}$ & $\begin{array}{l}\text { Chi-square test } \\
p<0.001 \\
p<0.001\end{array}$ \\
\hline $\begin{array}{l}\text { Policy A (high deductible) in Period } 5 \\
\text { Policy B (low deductible) in Period } 5\end{array}$ & $\begin{array}{l}\text { No illness } \\
0.91 \\
0.70 \\
n=1046\end{array}$ & $\begin{array}{l}\text { Any illness } \\
0.36 \\
0.96 \\
n=521\end{array}$ & $\begin{array}{l}\text { Chi-square test } \\
p<0.001 \\
p<0.001\end{array}$ \\
\hline $\begin{array}{l}\text { Policy A (high deductible) in Period } 6 \\
\text { Policy B (low deductible) in Period } 6\end{array}$ & $\begin{array}{l}\text { No illness } \\
0.95 \\
0.67 \\
n=1069\end{array}$ & $\begin{array}{l}\text { Any illness } \\
0.48 \\
0.97 \\
n=498\end{array}$ & $\begin{array}{l}\text { Chi-square test } \\
p<0.001 \\
p<0.001\end{array}$ \\
\hline $\begin{array}{l}\text { Policy A (high deductible) in Period } 7 \\
\text { Policy B (low deductible) in Period } 7\end{array}$ & $\begin{array}{l}\text { No illness } \\
0.92 \\
0.69 \\
n=1057\end{array}$ & $\begin{array}{l}\text { Any illness } \\
0.43 \\
0.96 \\
n=510\end{array}$ & $\begin{array}{l}\text { Chi-square test } \\
p<0.001 \\
p<0.001\end{array}$ \\
\hline $\begin{array}{l}\text { Policy A (high deductible) in Period } 8 \\
\text { Policy B (low deductible) in Period } 8\end{array}$ & $\begin{array}{l}\text { No illness } \\
0.93 \\
0.71 \\
n=695\end{array}$ & $\begin{array}{l}\text { Any illness } \\
0.57 \\
0.97 \\
n=872\end{array}$ & $\begin{array}{l}\text { Chi-square test } \\
p<0.001 \\
p<0.001\end{array}$ \\
\hline $\begin{array}{l}\text { Policy A (high deductible) in Period } 9 \\
\text { Policy B (low deductible) in Period } 9\end{array}$ & $\begin{array}{l}\text { No illness } \\
0.92 \\
0.74 \\
n=1069\end{array}$ & $\begin{array}{l}\text { Any illness } \\
0.45 \\
0.98 \\
n=498\end{array}$ & $\begin{array}{l}\text { Chi-square test } \\
p<0.001 \\
p<0.001\end{array}$ \\
\hline $\begin{array}{l}\text { Policy A (high deductible) in Period } 10 \\
\text { Policy B (low deductible) in Period } 10\end{array}$ & $\begin{array}{l}\text { No illness } \\
0.90 \\
0.75 \\
n=1058\end{array}$ & $\begin{array}{l}\text { Any illness } \\
0.50 \\
0.97 \\
n=509\end{array}$ & $\begin{array}{l}\text { Chi-square test } \\
p<0.001 \\
p<0.001\end{array}$ \\
\hline
\end{tabular}


participants who purchased high-deductible insurance and suffered any illness (moderate or severe) report LOW FEEL scores compared with those who did not suffer an illness. These individuals are likely to have experienced some regret at the outcome because they knew that they could have received higher claim payments if they had purchased low-deductible insurance. In contrast, among those who had bought low-deductible insurance, more than $95 \%$ of the respondents had HIGH FEEL scores when they suffered an illness in any period because they received higher claim payments than if they had purchased a high-deductible policy.

As shown in the columns in Table 2, when individuals did not suffer an illness, the proportion with HIGH FEEL scores is greater for those purchasing the high-deductible policy than the low-deductible one, as would be expected, given the lower premiums for the high-deductible policy. On the other hand, when individuals experienced either a moderate or severe illness, the proportion with HIGH FEEL scores was greater for those with a low-deductible policy because of their smaller out-of-pocket expenses. The difference in FEEL scores was statistically significant for both the row and column comparisons in all periods based on a chi-square test $(\mathrm{p}<0.001)$.

Do people switch insurance coverage after learning whether or not they had experienced an illness? The left panel of Table 3 examines the behavior of those who bought high-deductible insurance (Policy A) in any given period and shows that they are more likely to switch to low-deductible insurance (Policy B) in the next period if they experienced an illness than if they did not. The differences between the two percentages are statistically significant or close to being so in each period, except for Periods 4 and 9.

Surprisingly, those who suffered a moderate illness were more likely to switch to a low-deductible plan in Period 2 than those who suffered a severe illness. Possibly they thought that a severe illness was unlikely to reoccur, given that respondents were informed about its low probability, such that they treated it in the future as below their threshold level of concern, as revealed in other empirical studies of insurance purchasing behavior (Botzen et al., 2015; Chaudhry et al., 2018).

In Period 8, there was almost no difference in switching behavior between those experiencing a moderate or a severe illness, though both groups were more likely than the no-loss group to switch, possibly because individuals recognized that they had saved considerable money over time by purchasing a high- rather than low-deductible plan. When examined across all periods taken together, the differences in percentages between no loss and any loss were statistically significant using a chi-square test $(\mathrm{p}<0.001)$. The difference in proportion switching to a low-deductible plan was higher for those experiencing an illness in any period except the last one, with the 
Table 3. Numbers and percentages (in parentheses) of buyers who switch policies after no illnesses and any illness

\begin{tabular}{|c|c|c|c|c|c|c|}
\hline \multicolumn{4}{|c|}{$\begin{array}{l}\text { Switch from high deductible (Policy A) to low } \\
\text { deductible (Policy B) }\end{array}$} & \multicolumn{3}{|c|}{$\begin{array}{c}\text { Switch from low deductible (Policy B) to } \\
\text { high deductible (Policy A) }\end{array}$} \\
\hline Period & Total & No illness & Any illness & Total & No illness & Any illness \\
\hline 1 & $\begin{array}{l}517 \\
(26.1)\end{array}$ & $\begin{array}{l}347 \\
(23.6)\end{array}$ & $\begin{array}{l}170 \\
(31.2 *)\end{array}$ & $\begin{array}{l}1,050 \\
(15.4)\end{array}$ & $\begin{array}{l}711 \\
(17.4)\end{array}$ & $\begin{array}{l}339 \\
\left(11.2^{* *}\right)\end{array}$ \\
\hline 2 & $\begin{array}{l}544 \\
(26.3)\end{array}$ & $\begin{array}{l}253 \\
(21.7)\end{array}$ & $(30.2 * *)$ & $\begin{array}{l}1,023 \\
(11.1)\end{array}$ & $\begin{array}{l}458 \\
(12.5)\end{array}$ & $\begin{array}{l}565 \\
(10.1)\end{array}$ \\
\hline 3 & $\begin{array}{l}515 \\
(26.0)\end{array}$ & $\begin{array}{l}340 \\
(22.7)\end{array}$ & $\begin{array}{l}175 \\
\left(32.6^{* *}\right)\end{array}$ & $\begin{array}{l}1,052 \\
(11.3)\end{array}$ & $\begin{array}{l}716 \\
(11.7)\end{array}$ & $\begin{array}{l}336 \\
(10.4)\end{array}$ \\
\hline 4 & $\begin{array}{l}500 \\
(24.4)\end{array}$ & $\begin{array}{l}324 \\
(22.2)\end{array}$ & $\begin{array}{l}176 \\
(28.4)\end{array}$ & $\begin{array}{l}1,067 \\
(11.8)\end{array}$ & $\begin{array}{l}704 \\
(12.1)\end{array}$ & $\begin{array}{l}363 \\
(11.3)\end{array}$ \\
\hline 5 & $\begin{array}{l}504 \\
(26.4)\end{array}$ & $\begin{array}{l}341 \\
(22.9)\end{array}$ & $\begin{array}{l}163 \\
\left(33.7^{* *}\right)\end{array}$ & $\begin{array}{l}1,063 \\
(11.5)\end{array}$ & $\begin{array}{l}705 \\
(11.5)\end{array}$ & $\begin{array}{l}358 \\
(11.5)\end{array}$ \\
\hline 6 & $\begin{array}{l}493 \\
(27.8)\end{array}$ & $\begin{array}{l}319 \\
(22.9)\end{array}$ & $\begin{array}{l}174 \\
\left(36.8^{* * *}\right)\end{array}$ & $\begin{array}{l}1,074 \\
(10.2)\end{array}$ & $\begin{array}{l}750 \\
(11.9)\end{array}$ & $\begin{array}{l}324 \\
\left(6.5^{* *}\right)\end{array}$ \\
\hline 7 & $\begin{array}{l}466 \\
(26.0)\end{array}$ & $\begin{array}{l}314 \\
(21.7)\end{array}$ & $\begin{array}{l}152 \\
\left(34.9^{* *}\right)\end{array}$ & $\begin{array}{l}1,101 \\
(10.5)\end{array}$ & $\begin{array}{l}743 \\
(10.8)\end{array}$ & $\begin{array}{l}358 \\
(10.1)\end{array}$ \\
\hline 8 & $\begin{array}{l}461 \\
(27.6)\end{array}$ & $\begin{array}{l}205 \\
(23.4)\end{array}$ & $\begin{array}{l}256 \\
\left(30.9^{*}\right)\end{array}$ & $\begin{array}{l}1,106 \\
(11.9)\end{array}$ & $\begin{array}{l}490 \\
(11.2)\end{array}$ & $\begin{array}{l}616 \\
(12.5)\end{array}$ \\
\hline 9 & $\begin{array}{l}466 \\
(25.1)\end{array}$ & $\begin{array}{l}303 \\
(25.4)\end{array}$ & $\begin{array}{l}163 \\
(24.5)\end{array}$ & $\begin{array}{l}1,101 \\
(8.3)\end{array}$ & $\begin{array}{l}766 \\
(8.9)\end{array}$ & $\begin{array}{l}335 \\
(6.9)\end{array}$ \\
\hline
\end{tabular}

*Chi-square test (for difference from 'no illness') significant at $\mathrm{p}<0.1$.

$\because$ Chi-square test significant at $\mathrm{p}<0.05$.

$* * *$ Chi-square test significant at $\mathrm{p}<0.001$.

increase in switching ranging from $6 \%$ to $14 \%$, with a mean (over all periods) of $8.5 \%$.

The right panel of Table 3 shows that among those who purchased low-deductible insurance (Policy B) in any given period and who experienced no illnesses, the proportion switching to Policy A in the next period is the same or higher across all periods compared to those suffering any illness, except for Period 8 , where the difference is statistically nonsignificant $(\mathrm{p}=0.516)$. When the data from all periods are combined, the difference between the proportion switching to Policy A between no illness and any illness groups is statistically significant $(\mathrm{p}<0.001) .^{3}$ The effect of paying higher premiums but not having an illness and thus not making a claim led to a modestly greater rate of switching 
Table 4. Relationship of HIGH FEEL and any illness to Switch (odds ratios)

\begin{tabular}{|c|c|c|c|c|c|c|}
\hline \multirow{4}{*}{$\begin{array}{l}\text { Period } 1 \\
\text { R1 } \\
\text { R2 }\end{array}$} & \multicolumn{3}{|c|}{ High-deductible (Policy A) buyers } & \multicolumn{3}{|c|}{ Low-deductible (Policy B) buyers } \\
\hline & $n$ & HIGH FEEL & Any illness & $n$ & HIGH FEEL & Any illness \\
\hline & 517 & $0.42 * * *$ & - & 1050 & $0.20 * * *$ & - \\
\hline & 517 & $0.41 * * *$ & 0.97 & 1050 & $0.20 * *$ & 1.01 \\
\hline Period 2 & $n$ & HIGH FEEL & Any illness & $n$ & HIGH FEEL & Any illness \\
\hline $\mathrm{R} 1$ & 544 & $0.48 * * *$ & - & 1023 & $0.33 * *$ & - \\
\hline $\mathrm{R} 2$ & 544 & $0.52 * *$ & 1.14 & 1023 & $0.29 * *$ & 1.24 \\
\hline Period 3 & $n$ & HIGH FEEL & Any illness & $n$ & HIGH FEEL & Any illness \\
\hline R1 & 515 & $0.35 * * *$ & - & 1052 & $0.35 * *$ & - \\
\hline $\mathrm{R} 2$ & 515 & $0.34 * * *$ & 0.91 & 1052 & $0.32 * * *$ & 1.27 \\
\hline Period 4 & $n$ & HIGH FEEL & Any illness & $n$ & HIGH FEEL & Any illness \\
\hline $\mathrm{R} 1$ & 500 & $0.42 * * *$ & - & 1067 & $0.38 * * *$ & - \\
\hline $\mathrm{R} 2$ & 500 & $0.40 * * *$ & 0.90 & 1067 & $0.35 * *$ & 1.30 \\
\hline Period 5 & $n$ & HIGH FEEL & Any illness & $n$ & HIGH FEEL & Any illness \\
\hline & 504 & $0.40 * * *$ & - & 1063 & $0.31 * * *$ & - \\
\hline R2 & 504 & $0.41 * * *$ & 1.04 & 1063 & $0.25 * *$ & $1.63 * *$ \\
\hline Period 6 & $n$ & HIGH FEEL & Any illness & $n$ & HIGH FEEL & Any illness \\
\hline & 493 & $0.42 * * *$ & - & 1074 & $0.30 * * *$ & \\
\hline $\mathrm{R} 2$ & 493 & $0.53 * *$ & 1.44 & 1074 & $0.32 * * *$ & 0.79 \\
\hline Period 7 & $n$ & HIGH FEEL & Any illness & $n$ & HIGH FEEL & Any illness \\
\hline $\mathrm{R} 1$ & 466 & $0.26 * * *$ & - & 1101 & $0.26 * * *$ & - \\
\hline R2 & 466 & $0.25 * *$ & 0.95 & 1101 & $0.21 * *$ & $1.68 * *$ \\
\hline Period 8 & $n$ & HIGH FEEL & Any illness & $n$ & HIGH FEEL & Any illness \\
\hline $\mathrm{R} 1$ & 461 & $0.33 * * *$ & - & 1106 & $0.35 * * *$ & - \\
\hline R2 & 461 & $0.32 * * *$ & 0.94 & 1106 & $0.24 * * *$ & $1.90 * *$ \\
\hline Period 9 & $n$ & HIGH FEEL & Any illness & $n$ & HIGH FEEL & Any illness \\
\hline $\mathrm{R} 1$ & 466 & $0.52 * *$ & - & 1101 & $0.29 * * *$ & - \\
\hline $\mathrm{R} 2$ & 466 & $0.38 * * *$ & $0.58 * *$ & 1101 & $0.28 * *$ & 1.16 \\
\hline
\end{tabular}

*Chi-square test significant at $\mathrm{p}<0.1$.

$*$ Chi-square test significant at $\mathrm{p}<0.05$.

$* *$ Chi-square test significant at $\mathrm{p}<0.001$.

to a lower-priced Policy A, with $11.8 \%$ switching on average after suffering no illnesses, and $10.1 \%$ switching on average after suffering an illness.

Table 4 shows the results of two logistic regression analyses to explain the relative risk of switching in the next period as a function of FEEL (R1) and then adding LOSS as an explanatory variable (R2). If a variable does not affect the odds of switching, its regression coefficient should be unity. R1 in the left and right panels of Table 4 show that having a HIGH FEEL score compared to a LOW FEEL score induces a lower likelihood of 
switching (i.e., a coefficient less than 1 ) that is statistically significant in every period.

Adding a binary variable, LOSS, does not improve the explanatory power of R2 for high-deductible buyers, as shown by the nonsignificant p-values, except in Period 9 (left panel). For low-deductible buyers (right panel), LOSS as well as FEEL are statistically significant in Periods 5, 7, and 8. Low-deductible buyers in Periods 5, 7, and 8 who suffered an illness were more likely to switch to a high-deductible plan, possibly because they felt that the illness is less likely to reoccur in the next period.

\section{Discussion}

The FEEL question was designed to measure the influence of emotions on health insurance decision-making, a variable that is not traditionally included in expected utility models. Alternative measures defining 'emotions' that probe more deeply into how feelings influence decision-making were not examined. Alternative interpretations of the nature of the influence described by the FEEL question are possible and should be explored further via controlled experiments and field surveys.

Our findings do indicate that other factors besides probability and outcomes influence the decision-making process when choosing between high- and lowdeductible plans for a large minority of subjects. Our logit analysis did produce the strong result that, after controlling for FEEL, experiencing an illness did not influence switching of insurance plans. Exploring the factors influencing actual switching behavior from a high- to a low-deductible plan following a loss for those who had maintained high-deductible policies and experienced few losses over an extend time period would be useful future research.

\section{Conclusions}

About half of our respondents made health insurance choices over all periods that were consistent with expected utility maximization. Since the administrative loadings for policies in our experiment were below those actually prevailing in exchanges, the proportion of experimental subjects choosing the high-deductible option was smaller than it would have been had the actual loadings been used. ${ }^{4}$

4 One limitation of the experiment is that the absence of real monetary payoffs may have biased estimates toward zero. Our findings of significant results in many cases are robust, but we would like to incorporate monetary rewards in a future experiment if possible. 
In our experiment, many individuals changed their plans from high- to lowdeductible ones after experiencing an illness. This finding implies that, for these individuals, the choice of deductible insurance plans was not based on deliberative tradeoffs between premium costs and risk-reduction benefits of known and well-understood loss probabilities. For example, some people changed their insurance coverage in response to previous-period loss experience, even though they were informed of the same unchanging loss probabilities each period. Hence, change in risk cannot be a rationale for switching insurance coverage. In addition, many individuals switched from one plan to another if they had regrets about their insurance purchase decision in the previous period as indicated by their LOW FEEL scores after suffering an illness, even though they had been given the same value for the loss probability in the next period. It is possible that they failed to notice that the probabilities were always the same and unaffected by previous-period loss experience, but the repetition of the likelihood of a illness at the beginning of each period makes it unlikely that they would have made that inference.

\section{Acknowledgments}

The authors thank the referees and Carol Heller for helpful feedback on this paper. Lindsey Patterson provided excellent research assistance.

\section{Financial support}

Support for this research comes from the Travelers-Wharton Partnership for Risk Management and Leadership Fund and the Wharton Risk Management and Decision Processes Center's Managing and Financing Extreme Events project.

\section{References}

Abaluck, J. and J. Gruber (2011), 'Choice inconsistencies among the elderly: Evidence from plan choice in the Medicare Part D Program', American Economic Review, 101(4): 1180-1210. doi:10.1257/aer.101.4.1180.

Bell, D. (1982), 'Regret in Decision Making Under Uncertainty', Operations Research, 30: 961-981. Bhargava, S., G. Loewenstein and J. Sydnor (2017), 'Choose to Lose: Health Plan Choices from a Menu with Dominated Option', The Quarterly Journal of Economics, 132(3): 1319-1372.

Botzen, W. W., H. Kunreuther and E. Michel-Kerjan (2015), 'Divergence between individual perceptions and objective indicators of tail risks: Evidence from floodplain residents in New York City', Judgment and Decision Making, 10(4): 365-385.

Braun, M. and A. Muermann (2004), 'The impact of regret on the demand for insurance', Journal of Risk and Insurance, 71: 737-767. 
Centers for Medicare and Medicaid Services (2017), 'Health insurance exchange public use files', Available at: https:/www.cms.gov/cciio/resources/data-resources/marketplace-puf.html

Chaudhry, S. J., M. Hand and H. Kunreuther (2018), 'Extending the Time Horizon: Elevating Concern for Rare Events by Communicating Losses Over a Longer Period of Time', Working Paper. \# 2018-06 (August).

HealthPocket (2017), Available at www.healthpocket.com.

Kaiser Family Foundation 2017. (2017), 'Employer health benefits survey', Available at: https://www. kff.org/health-costs/report/2017-employer-health-benefits-survey/

Ketcham, J. D., C. Lucarelli, E. Miravete, and M. C. Roebuck (2012), 'Sinking, swimming, or learning to swim in Medicare Part D', American Economic Review, 102(6): 2639-2673.

Ketcham, J. D., C. Lucarelli, and C. A. Powers (2015), 'Paying attention or paying too much in Medicare Part D', American Economic Review, 105(1): 204-233 (page 206). doi:10.1257/ aer.20120651.

Loomes, G. and R. Sugden (1982), 'Regret theory: an alternative theory of rational choice under uncertainty', Economic Journal, 92: 805-824.

McGuire, T. G. (2012), 'The Demand for Health Insurance', in Pauly, McGuire, and Barros, eds, Handbook of Health Economics Volume 2, Amsterdam: Elsevier, 317-396.

Neipp, J., and R. Zeckhauser (1985), 'Persistence in the choice of health plans', Advances in Health Economics and Health Services Research, 6: 47-72.

Phelps, C. E. (1973), 'The demand for health insurance: a theoretical and empirical investigation', (R-1054-OEO), The RAND Corporation: Santa Monica, CA.

Samuelson, W. and R. Zeckhauser (1988), 'Status quo bias in decision making', Journal of Risk and Uncertainty, 1: 7-29. 